\title{
AN INTEGRATED MULTI-OBJECTIVE OPTIMIZATION MODEL FOR SOLVING THE CONSTRUCTION TIME-COST TRADE-OFF PROBLEM
}

\author{
Choongwan $\mathrm{KOO}^{\mathrm{a}}$, Taehoon $\mathrm{HONG}^{\mathrm{a}}$, Sangbum $\mathrm{KIM}^{\mathrm{b}}$ \\ ${ }^{a}$ Department of Architectural Engineering, Yonsei University, 120-749 Seoul, Korea \\ ${ }^{b}$ Department of Civil and Environmental Engineering, Dongguk University, 100-715 Seoul, Korea
}

Received 07 Jun 2012; accepted 28 Aug 2012

\begin{abstract}
As construction projects become larger and more diversified, various factors such as time, cost, quality, environment, and safety that need to be considered make it very difficult to make the final decision. This study was conducted to develop an integrated Multi-Objective Optimization (iMOO) model that provides the optimal solution set based on the concept of the Pareto front, through the following six steps: (1) problem statement; (2) definition of the optimization objectives; (3) establishment of the data structure; (4) standardization of the optimization objectives; (5) definition of the fitness function; and (6) introduction of the genetic algorithm. To evaluate the robustness and reliability of the proposed iMOO model, a case study on the construction time-cost trade-off problem was analyzed in terms of effectiveness and efficiency. The results of this study can be used: (1) to assess more than two optimization objectives, such as the initial investment cost, operation and maintenance cost, and $\mathrm{CO}_{2}$ emission trading cost; (2) to take advantage of the weights as the real meanings; (3) to evaluate the four types of fitness functions; and (4) to expand into other areas such as the indoor air quality, materials, and energy use.
\end{abstract}

Keywords: multi-objective optimization, pareto front, non-dominated solution, fitness function, construction management.

\section{Introduction}

The Construction Management Association of America (CMAA) defines Construction Management (CM) as a professional service that applies effective management techniques to control various standards, such as the time, cost, quality, environment, and safety, under a series of processes from the project planning phases to operation and maintenance phase. CM is defined as a management system created for the successful performance of a project from the owner's viewpoint (Henderickson, $\mathrm{Au}$ 1989; CMAA 1999; Unnikrishnan et al. 2009).

Various complex and large-scale projects such as superhigh-rise buildings, green buildings, super-long-span bridges, u-city projects, and urban regeneration projects have recently emerged. In the early stage of a project, it is important to recognize the role of a construction manager or contractor in effective and reliable management of a project. For instance, a super-high-rise building project requires careful review of new techniques or methods in terms of structural and construction engineering. Based on the review, a plan should be established to engage appropriate labor and equipment. Such decision-making ultimately affects the time, cost, and quality, among other factors, of a project, and thus, determines the outcome of the project as the final decision. The larger the project scales, the more varied factors for consideration are generated. This makes it very difficult to make the final decision. It becomes increasingly difficult to review all possible combinations of factors for the best decisions, which leads to obstacles in obtaining reliability. To solve this problem, experts should be involved or a sophisticated decision support system should be developed (Pagnoni 1990; Adeli, Hung 1995; Adeli, Sarma 2006).

As the delivery methods (i.e. the design and build, best-value contract, management contract, prime contracting, build-operate-transfer, partnering, etc.) are diversified, the target standards on project performance (i.e. the time, cost, quality, environment, etc.) likewise become diversified based on the characteristics of a project (Zheng et al. 2004; Ammar 2011). For instance, the best-value contract grants a higher value to quality than to time and cost (Ansell et al. 2009; Lam et al. 2009; Asmar et al. 2010; Sullivan 2011). LEED certification projects give priority to the environmental standards. Nevertheless, while meeting the construction contract time, there should be no increase in the cost or a reduction in quality (Hegazy 1999; Hegazy, Ersahin 2001; Rogoža et al. 2006). 
This study was conducted to develop an integrated multi-objective optimization (iMOO) model capable of comprehensively analyzing various standards that are traditionally considered in the construction industry, such as time and cost, and of determining an optimal solution according to the following procedure: (1) through an extensive literature review, a preliminary analysis was conducted on various methodologies applied in the past (i.e. heuristic, mathematical programming, and genetic algorithms) and the limitations of these methodologies were analyzed; and (2) by solving these limitations, a model with improved flexibility or applicability and usability was developed that can be applied to various areas related to multi-objective optimization. Two criteria were used to assess the robustness and reliability of the proposed iMOO model: effectiveness in terms of the quality of the generated optimal solution set; and efficiency in terms of computational time.

\section{Conventional multi-objective optimization techniques}

There have been several studies on multi-objective optimization, and various methodologies have been implemented, including heuristics, mathematical programming, and genetic algorithms.

First, using heuristic methods, previous studies hoped to solve the Time-Cost Trade-off Problem (TCTP). Based on the rule of thumb, this methodology may provide a good result, but it cannot guarantee that the result would always be the optimal solution. Additionally, since the result is not presented in terms of the range of possible solutions, this methodology is inappropriate for use in analyzing various scenarios, such as in Fondahl's method, Prager's structural model, Moshlhi's structural stiffness method, and Siemens's effective cost slope model (Fondahl 1961; Prager 1963; Siemens 1971; Moselhi 1993).

Second, some methodologies, such as linear programming and integer programming, hoped to solve TCTP by applying mathematical programming methods. While linear programming may be appropriate in determining the existence of a linear time-cost relationship, it is limited in determining the existence of a discrete time-cost relationship. To solve this problem, integer programming was introduced (Liu et al. 1995; Burns et al. 1996). Integer programming, however, requires too much time and effort to model a large number of activities or complex relationships. Many studies have pointed out the disadvantages of heuristics and mathematical methods, the most serious of which is that they are not appropriate for dealing with more than one objective.

Third, to solve this issue, several studies have defined the trade-off among management indices as multi-objective optimization problems and introduced genetic algorithms (Goldberg 1989; Adeli, Cheng 1993; Li, Love 1997; Elbeltagi et al. 2005; Ng, Zhang 2006; Chen, Weng 2009). Feng et al. (1997) introduced the concept of multi-objective optimization to optimize the time and cost at the same time. However, this approach uses the convex hull concept, which is also used in linear programming and thus has a limitation in providing the actual optimal solution. Gen and Cheng (2000) hoped to solve TCTP using the adaptive weight approach (AWA), but they were only able to produce an optimal solution when several assumptions were satisfied. Zheng et al. (2004) aimed to solve TCTP using the modified adaptive weight approach, which improved the disadvantages of AWA. Zheng et al. (2005a) and Zheng and Ng (2005b) also proposed the range of possible solutions by introducing the concept of Pareto ranking and niche formation.

Fourth, aside from TCTP, several studies have considered the quality, environment, and productivity at the same time (Hsieh, Liu 2004; Balling et al. 2004; Huang et al. 2009; Jiang et al. 2011; Liu et al. 2012; Simanaviciene et al. 2012). El-Rayes and Kandil (2005) tried to solve the time-cost-quality trade-off problem in highway construction. Marseguerra et al. (2004) and Martorell et al. (2005) applied the concept of multi-optimization using genetic algorithms to solve the optimization problem on the technical specifications and maintenance activities in nuclear power plants. Carvalho et al. (2012) conducted a study to assess the economic and environmental aspects on a trigeneration system.

\section{Motivation from previous studies}

Through an extensive literature reviews with regards to the multi-optimization, the limitations of the methodologies applied to the existing research were identified. At the same time, the advantages of these methodologies were determined. Based on the results, this study aims to develop more intuitive, simplified, applicable and flexible model (i.e. research team named it "iMOO model") to solve the multi-optimization problems. The following are several motivations for developing the iMOO model:

- The iMOO model should guarantee that the results would always be the optimal solution, which could not be achieved using heuristic method.

- The iMOO model should be simplified to minimize the time and effort spent to model a large number of activities or complex relationship, which could not be achieved using linear and integer programming.

- The iMOO model should provide an optimal solution set based on the concept of the Pareto front. Accordingly, the reliability on the final results should be improved (refer to Figs 1 and 2).

- The iMOO model should have improved flexibility or applicability depending on the problem statement and should be able to easily handle more than two optimization objectives (refer to Fig. 3).

- The iMOO model should have improved usability by simplifying the complicated processes and equations shown in previous studies (Feng et al. 1997; Goldberg 1989; Li, Love 1997; Gen, Cheng 2000; Zheng et al. 2004, 2005a; Zheng, Ng 2005b) (refer to Section 3, "Model implementation"). 
- The iMOO model adopts two criteria for improving the performance of the models proposed in previous studies: (1) effectiveness in terms of the quality of the generated optimal solution set; and (2) efficiency in terms of computational time (refer to Section 4, "Model application").

- The iMOO model realizes an optimization algorithm using a genetic algorithm.

Figures 1 and 2 show the concept of the Pareto front (i.e. non-dominated set) and the optimal solution set, respectively (Chen and Weng 2009). As shown in Figure 1, the alternatives for the Pareto front were not superior to the other alternatives in terms of both of two optimization objectives (i.e. $Z_{A}$ and $Z_{B}$, which represent the time, cost, quality, environment, etc.). The Pareto front signifies a set of alternatives whose superiority cannot be easily determined.

Figure 2 explains Areas (1)-(4), which are compartmentalized based on Alternative $\alpha$. First, all alternatives in Area (1) are superior to the Alternative $\alpha$ in terms of both two optimization objectives, $Z_{A}$ and $Z_{B}$ (i.e. the area that Alternative $\alpha$ is dominated by). Moreover, within Area (1), the set of alternatives whose superiority cannot be easily determined is called the optimal solution set. Second, Areas (2) and (3), compared to Alternative $\alpha$, signify indifferent areas in which one of the two optimization objectives is superior and the other is inferior. Third, all alternatives in Area (4) are inferior to the Alternative $\alpha$ in terms of both of two optimization objectives, $Z_{A}$ and $Z_{B}$ (i.e. the area that Alternative $\alpha$ dominates).

The proposed iMOO model presents the process of producing the optimal solution set based on the two concepts explained in Figures 1 and 2 - the Pareto front and the optimal solution set. This approach can also be applied identically to more than two objectives. Figure 3 conceptually shows three optimization objectives (for which it was assumed that an index is better when $Z_{A}$ and $Z_{B}$ are smaller and when $Z_{C}$ is larger). This shows that the proposed iMOO model can be easily expanded to multiple dimensions.

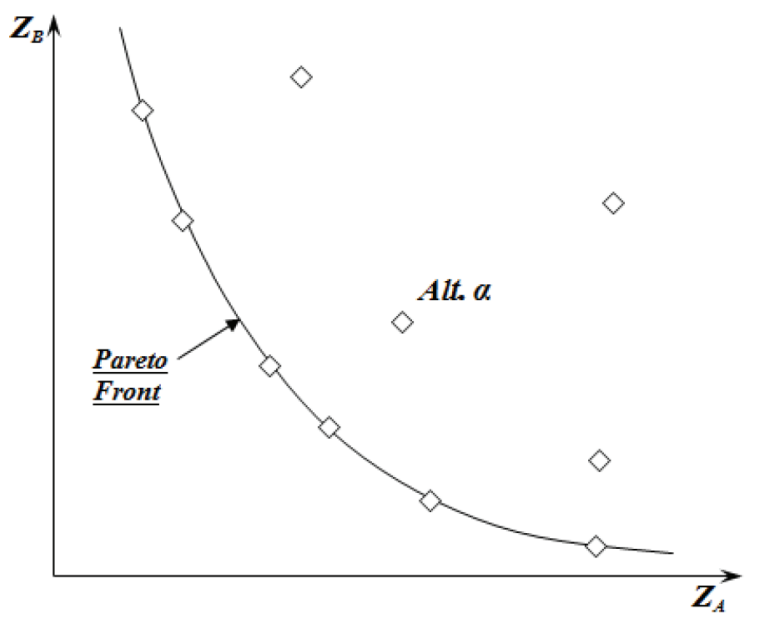

Fig. 1. Pareto front in the two-objective space

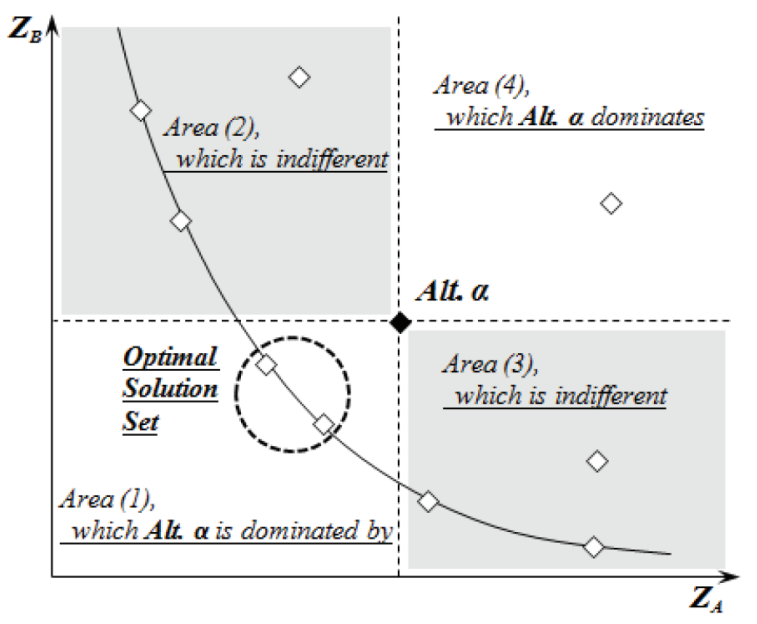

Fig. 2. Non-dominated area and the optimal solution set

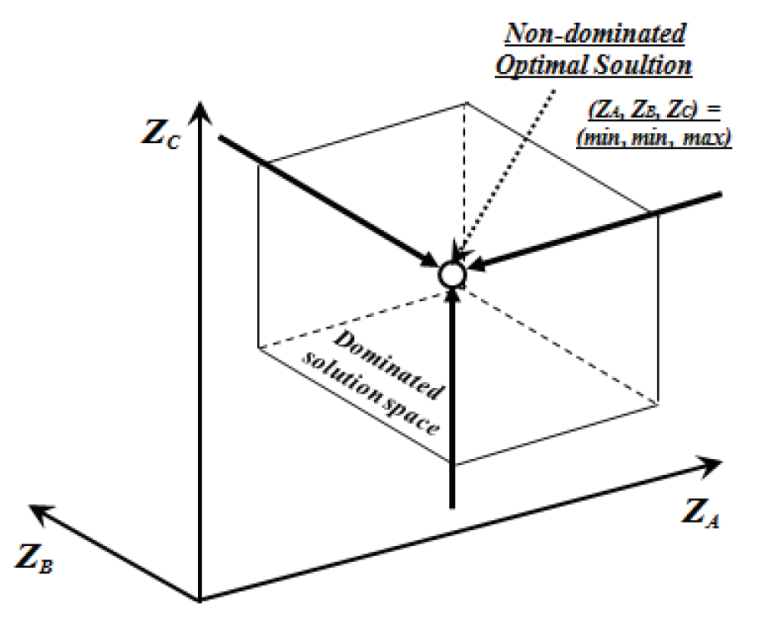

Fig. 3. Non-dominated optimal solution in the three-objective space

\section{Model implementation}

Based on the motivations for this study that were explained in Section 2, "Motivation from the previous studies", the following core engine of the iMOO model was developed.

The values of the optimization objectives, which are defined by the characteristics of a project, should be standardized. First, the maximum extreme point $\left(Z^{+}\right)$and the minimum extreme point $\left(Z^{-}\right)$, i.e. the two extreme points within the whole criteria space, can be found using Eqns (1) and (2) suggested by Gen and Cheng (2000). Moreover, the hyperplane, which is used to find the optimal solution set, can be established based on the two extreme points (here, it was assumed that an index is better when $Z_{A}$ and $Z_{B}$ are smaller) (refer to Fig. 4):

$$
\begin{aligned}
& Z^{+}=\left\{Z_{A}^{\max }, Z_{B}^{\max }\right\} ; \\
& Z^{-}=\left\{Z_{A}^{\min }, Z_{B}^{\min }\right\},
\end{aligned}
$$


where: $Z^{+}$is the maximum extreme point; $Z^{-}$is the minimum extreme point; $Z_{A}{ }^{\max }$ and $Z_{B}{ }^{\max }$ are the maximum value for the optimization objectives of $A$ and $B$, respectively; and $Z_{A}{ }^{\text {min }}$ and $Z_{B}{ }^{\text {min }}$ are the minimum value for the optimization objectives of $A$ and $B$, respectively.

Second, all points within the whole criteria space should be standardized using Eqns (3) and (4):

$$
\begin{aligned}
& S_{A}=\frac{Z_{A}-Z_{A}^{\min }}{Z_{A}^{\max }-Z_{A}^{\min }} ; \\
& S_{B}=\frac{Z_{B}-Z_{B}^{\min }}{Z_{B}^{\max }-Z_{B}^{\min }},
\end{aligned}
$$

where: $S_{A}$ is the standardized value for the $Z_{A}$; and $S_{B}$ is the standardized value for the $Z_{B}$.

As the original values for the optimization objectives of $A$ and $B$ are converted into standardized values between 0 and 1 , several advantages can be obtained:

- The effect from the non-identical unit between the optimization objectives of $A$ and $B$ that are applied to the fitness function can be removed in advance.

- Gen and Cheng (2000) did not solve the problem of a zero division scenario. Zheng et al. (2005a) and Zheng and $\mathrm{Ng}$ (2005b) attempted to solve this issue using several stages of processes, complicated equations, and random number $\tau$ (between 0 and 1). This study could solve this problem using a simplified process called the standardization of optimization objectives.

- By simplifying the optimization process and equation, this study offers flexibility - i.e. it can easily access various applied problems.

- According to the project characteristics and the owner's requirements, the weight value of the optimization objectives can be applied. Gen and Cheng (2000), Zheng et al. (2005a) and Zheng and Ng (2005b) also used a weighed value, but since their process did not have a stage where the optimization objectives were standardized, the weighed value cannot be a weighed value in its purest sense.

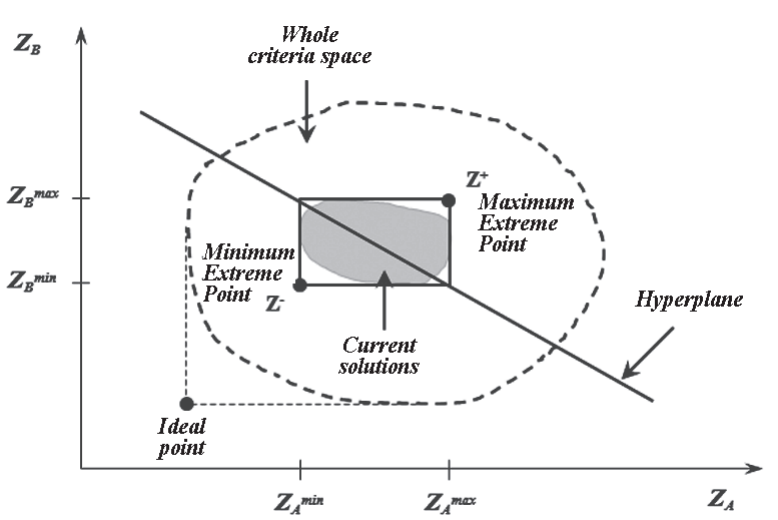

Fig. 4. Two extreme points and the hyperplane
- The model can help facilitate understanding and solve the problems on more than two optimization objectives through the multi-dimensional concept.

As shown in Figure 5, the model consists of four types of fitness functions. Based on the characteristics of the optimization objectives that were defined according to the project characteristics, an appropriate fitness function can be selected. A concrete example was explained in Section 4 "Model Application". As mentioned, all points can be standardized using Eqns (3) and (4) (refer to Fig. 5). A weight value can be found through the significance evaluation of each optimization objective. In this study, the weighted Euclidean distance, as shown in Eqn (5), was used:

$w E d_{x, b}=\sqrt{\sum_{i=1}^{n} w_{i} \times\left(x_{i}-b_{i}\right)^{2}}, 0 \prec w_{i} \prec 1$ and $\sum_{i=i}^{n} w_{i}=1$,

where: $w E d_{x, b}$ is the weighted Euclidean distance between $x$ and $b ; x_{i}$ is the value of the $i$-th measure for the particular data; $b_{i}$ is the corresponding benchmark value ( 0 or 1 ) for the value of $x_{i}$; and $w_{i}$ is the weight value for the $i$-th measure.

There are many methods for calculating the weight value (e.g. AHP based on interviews with specialists, the will of the decision-maker, or statistical methods, etc.), but these methods were not considered in this study. Four types of fitness functions are as follows:

(1) In case of minimizing the value for the optimization objective of $A$, and minimizing the value for the optimization objective of $B$ :

$$
\begin{aligned}
& \text { Fitness Function }(i) \\
& \qquad=\sqrt{W_{A} \times\left(S_{A}-0\right)^{2}+W_{B} \times\left(S_{B}-0\right)^{2}},
\end{aligned}
$$

where: the optimization process is continued until the Fitness Function (i) meets the minimum value; $W_{A}$ is the relative weight defined by the final decision-maker for minimizing the value of the optimization objective of $A$; and $W_{B}$ is the relative weight defined by the final decision-maker for minimizing the value of the optimization objective of $B$. For instance, if the optimization objectives of $A$ and $B$ are time and cost, respectively, the

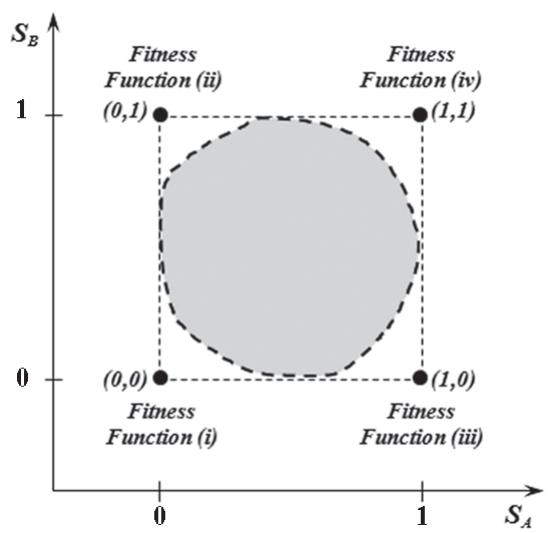

Fig. 5. Concept of the four types of fitness functions 
two variables are optimized if they are both closer to the minimum value.

(2) In case of minimizing the value for the optimization objective of $A$, while maximizing the value for the optimization objective of $B$ :

$$
\begin{aligned}
& \text { Fitness Function (ii) } \\
& \qquad=\sqrt{W_{A} \times\left(S_{A}-0\right)^{2}+W_{B} \times\left(1-S_{B}\right)^{2}},
\end{aligned}
$$

where: for instance, if the optimization objectives of $A$ and $B$ are cost and quality, respectively, the optimization objective of $A$ (cost) is optimized if it is closer to the minimum value, whereas the optimization objective of $B$ (quality) is optimized if it is closer to the maximum value.

(3) In case of maximizing the value for the optimization objective of $A$, while minimizing the value for the optimization objective of $B$ :

$$
\begin{aligned}
& \text { Fitness Function(iii) } \\
& \qquad=\sqrt{W_{A} \times\left(1-S_{A}\right)^{2}+W_{B} \times\left(S_{B}-0\right)^{2}},
\end{aligned}
$$

where: for instance, if the optimization objectives of $A$ and $B$ are sustainability and cost, respectively, the optimization objective of $A$ (sustainability) is optimized if it is closer to the maximum value, whereas the optimization objective of $B$ (cost) is optimized if it is closer to the minimum value.

(4) In case of maximizing the value for the optimization objective of $A$, and maximizing the value for the optimization objective of $B$ :

$$
\begin{aligned}
& \text { Fitness Function (iv) } \\
& \qquad=\sqrt{W_{A} \times\left(1-S_{A}\right)^{2}+W_{B} \times\left(1-S_{B}\right)^{2}},
\end{aligned}
$$

where: for instance, if the optimization objectives of $A$ and $B$ are productivity and safety, respectively, two variables are optimized if they are both closer to the maximum value.

The iMOO model can solve all possible problems with four types of fitness functions (refer to Fig. 5). Moreover, the iMOO model can solve the problems on more than two optimization objectives through the multidimensional concept (refer to Fig. 3).

(5) In case of minimizing the value for the optimization objectives of $A$ and $B$, and maximizing the value for the optimization objective of $C$ :

Fitness Function (v)

$=\sqrt{W_{A} \times\left(S_{A}-0\right)^{2}+W_{B} \times\left(S_{B}-0\right)^{2}+W_{C} \times\left(1-S_{C}\right)^{2}},(10)$

where: for instance, if the optimization objectives of $A$, $B$, and $C$ are cost, time, and environment, respectively, the optimization objectives of $A$ (cost) and $B$ (time) are optimized if they are closer to the minimum value, while the optimization objective of $C$ (environment) is optimized if it is closer to the maximum value.

\section{Model application}

The iMOO model proposed in this study was developed as a computer-aided program based on the following six- phase process: (1) problem statement; (2) definition of the optimization objectives; (3) establishment of the data structure; (4) standardization of the optimization objectives; (5) definition of the fitness function; and (6) introduction of the genetic algorithm. To evaluate the robustness and reliability of the proposed iMOO model, a case study on the construction TCTP was analyzed in terms of effectiveness and efficiency. In order to illustrate the concept of the proposed iMOO model more easily as well as to evaluate the robustness and reliability of the iMOO model more clearly, the case study used in Liu et al. (1995) and Zheng et al. (2005b) was applied to the iMOO model in this study.

\subsection{Problem statement}

In a construction project, the indices that the owner or the project manager is most interested in are the time, cost, quality, and environment. These indices have a trade-off relationship since there are so many considerations in construction project, i.e. construction materials, construction methods, equipment, labors, etc. For instance, applying new technology to reduce the project time or improve the external appearance or the residential environment increases the project cost. If the budget is insufficient, it is difficult to undertake measures to reduce time or improve the quality. Accordingly, a reasonable method for determining the optimal solution is required to solve such a trade-off relationship while satisfying the limited budget, contract period, and minimum quality requirements.

\subsection{Definition of optimization objectives}

Traditionally, it is project time and cost that are most strongly bound by a trade-off relationship in construction project. Once design alternatives or construction methods that satisfy the minimum requirements of owner are selected, project manager reviews them in terms of the time and cost and then makes the final decision. Thus, in this study, the time and cost are defined as the optimization objectives in performing the model application. The two objectives can be calculated using Eqs (11) and (12):

$$
\text { Project Time }=\sum_{i=1}^{l} T_{i}^{n},
$$

where: $T_{i}^{n}$ is the duration of activity $(i)$ on the critical path using resource utilization $(n)$ and $l$ is the number of activities. To establish the critical path in the activity network, the critical path method is used to calculate the activity time and flow.

$$
\text { Project Cost }=\sum_{i=1}^{l}\left[M_{i}^{n}+\left(T_{i}^{n} \times R_{i}^{n}\right)\right]
$$

where: $M_{i}^{n}$ is the direct cost of activity $(i)$ using resource utilization $(n) ; T_{i}^{n}$ is the time of activity $(i)$ using resource utilization $(n) ; R_{i}^{n}$ is the daily cost rate in \$/day using resource utilization $(n)$; and $l$ is the number of activities. 


\subsection{Establishment of the data structure}

In order to derive the optimal solution for the aforementioned optimization objectives, the basic information on each variable should be determined and their relationship should be established. Figure 6 shows the seven activities and their relationship in the case used in Liu et al. (1995) and Zheng and $\mathrm{Ng}$ (2005b). Table 1 shows the description of the case study, i.e. activities and their relationship, construction methods applicable for each activities and their duration and direct cost. Generally, if the duration of the project increases, the indirect cost may increase even if the direct cost is reduced. This relationship leads to an increase in the total cost. In order to define such a relationship, as determined by Zheng and $\mathrm{Ng}$ (2005b), the indirect cost was set at $\$ 500 /$ day in this study.

\subsection{Standardization of optimization objectives}

The heuristic method was used to calculate the maximum extreme point $\left(Z^{+}\right)$and the minimum extreme point $\left(Z^{-}\right)$, i.e. the two extreme points within the whole criteria space. Since the goal was to minimize both two-optimization objectives in the case, the maximum extreme point $\left(Z^{+}\right)$ based on Eqn (1) became the most undesirable point and the minimum extreme point $\left(Z^{-}\right)$based on Eqn (2) became the ideal point:

- Ideal point: $Z^{-}$(time, cost $)=(60,143,000)$;

- Most undesirable point: $Z^{+}$(time, cost $)=(105,203,200)$.

The values are located on the original coordinate axis (refer to Fig. 4). To define the fitness function and derive the optimal solution, a new coordinate axis between 0 and 1 should be created through the standardization process for these values using Eqns (3) and (4) (refer to Fig. 5).

\subsection{Definition of the fitness function}

As illustrated in Section 4.4 "Standardization of optimization objectives", the goal was to minimize both two-optimization objectives. Accordingly, the Fitness Function ( $i$ ) presented in Eqn (6) was used. The ideal point corresponded to $(0,0)$ on the standardized coordinate axis (refer to Fig. 5). As a result, the combination at which the Fitness Function ( $i$ ) had the minimum value is the optimal solution.

\subsection{Introduction of the genetic algorithm}

A genetic algorithm (GA) was used as a search algorithm for determining the optimal solution of the fitness

Table 1. Description of the case study

\begin{tabular}{|c|c|c|c|c|c|c|}
\hline $\begin{array}{l}\text { Activity } \\
\text { description }\end{array}$ & $\begin{array}{l}\text { Activity } \\
\text { number }\end{array}$ & $\begin{array}{l}\text { Precedent } \\
\text { activity }\end{array}$ & & Construction methods & $\begin{array}{l}\text { Duration } \\
\text { (days) }\end{array}$ & $\begin{array}{l}\text { Direct cost } \\
(\$)\end{array}$ \\
\hline \multirow{3}{*}{ Site preparation } & \multirow{3}{*}{1} & \multirow{3}{*}{-} & 1 & Crew $1+$ Equipment 1 & 14 & 23,000 \\
\hline & & & 2 & Crew $2+$ Equipment 2 & 20 & 18,000 \\
\hline & & & 3 & Crew $3+$ Equipment 3 & 24 & 12,000 \\
\hline \multirow{5}{*}{ Forms and rebar } & \multirow{5}{*}{2} & \multirow{5}{*}{1} & 1 & Method 1 & 15 & 3,000 \\
\hline & & & 2 & Method 2 & 18 & 2,400 \\
\hline & & & 3 & Method 3 & 20 & 1,800 \\
\hline & & & 4 & Method 4 & 23 & 1,500 \\
\hline & & & 5 & Method 5 & 25 & 1,000 \\
\hline \multirow{3}{*}{ Excavation } & \multirow{3}{*}{3} & \multirow{3}{*}{1} & 1 & Equipment 1 & 15 & 4,500 \\
\hline & & & 2 & Equipment 2 & 22 & 4,000 \\
\hline & & & 3 & Equipment 3 & 33 & 3,200 \\
\hline \multirow{3}{*}{$\begin{array}{l}\text { Precast concrete } \\
\text { girder }\end{array}$} & \multirow{3}{*}{4} & \multirow{3}{*}{1} & 1 & Method 1 & 12 & 45,000 \\
\hline & & & 2 & Method 2 & 16 & 35,000 \\
\hline & & & 3 & Method 3 & 20 & 30,000 \\
\hline \multirow{4}{*}{$\begin{array}{l}\text { Pour foundation } \\
\text { and piers }\end{array}$} & \multirow{4}{*}{5} & \multirow{4}{*}{2,3} & 1 & Method 1 & 22 & 20,000 \\
\hline & & & 2 & Method 2 & 24 & 17,500 \\
\hline & & & 3 & Method 3 & 28 & 15,000 \\
\hline & & & 4 & Method 4 & 30 & 10,000 \\
\hline \multirow{3}{*}{$\begin{array}{l}\text { Deliver PC } \\
\text { girders }\end{array}$} & \multirow{3}{*}{6} & \multirow{3}{*}{4} & 1 & Railroad & 14 & 40,000 \\
\hline & & & 2 & Truck & 18 & 32,000 \\
\hline & & & 3 & Barge & 24 & 18,000 \\
\hline \multirow{3}{*}{ Erect girders } & \multirow{3}{*}{7} & \multirow{3}{*}{5,6} & 1 & Crane $1+$ Crew 1 & 9 & 30,000 \\
\hline & & & 2 & Crane $2+$ Crew 2 & 15 & 24,000 \\
\hline & & & 3 & Crane $3+$ Crew 4 & 18 & 22,000 \\
\hline
\end{tabular}


function. In a GA, the decision variables that affect the optimization objectives are defined as chromosomes. Such chromosomes consist of various genes. In this study, each gene in the chromosome signified each activity in the network defined in Figure 6.

As shown in Figure 7, the number on each gene signified the construction method that performed each activity (refer to Table 1). The result value of fitness function was calculated by applying the properties (i.e. time and cost) of the construction method. Additional information on the fundamentals of multi-objective optimization and GA can be found in the related references (Certa et al. 2011; Elbehairy et al. 2006; Elegbede, Adjallah 2003; Geem 2010; Kandil et al. 2010; Konak et al. 2006; Moradi et al. 2011; Sayin, Kouvelis 2005; Šešok, Belevicius 2008; Šešok et al. 2010; Šostak, Vakrinien 2011; Venskus et al. 2010). In this study, a software program called 'OptQuest' (an optimization tool that runs with a software program called 'Crystal Ball') was used to introduce the GA.

\section{Results and discussion}

This research aims to develop an iMOO model for solving a multi-objective optimization problem, which determines the optimal solution set based on the concept of the Pareto front. Toward this end, this research team introduced the GA as a search algorithm and also simplified the complicated process and equation. Thus, the robustness and reliability of the proposed iMOO model was enhanced in terms of effectiveness and efficiency.

Figure 8 shows the list of 1,000 highly ranked populations generated through the GA in the scatter diagram on the original coordinate axis. The dotted curve at the bottom left of the diagram signify the Pareto front. As explained in Section 4.4 "Standardization of optimization

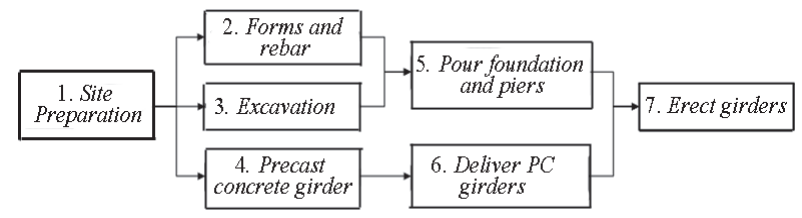

Fig. 6. Activity network of the case study



Fig. 7. Description of chromosome objectives," the coordinate axis should be standardized before the fitness function is defined.

Figure 9 shows the list of the 250 highly ranked populations generated through the GA in the scatter diagram on the standardized coordinate axis. The diagram was transformed into the same scale on the standardized axis. As shown in Figure 9, all 250 highly ranked populations existed near the ideal point $(0,0)$ based on the longitudinal section and cross-section (compared to Fig. 8). This result showed that the reliability of the proposed iMOO model was improved as the process proceeded.

As shown in Figure 10, the distribution of the 50 highly ranked populations was closer to the ideal point $(0,0)$ (compared to Fig. 9). This result signifies that the two optimization objectives (time and cost) were being improved at the same time as the process proceeded.

To assess the robustness and reliability of the proposed iMOO model, two criteria were used: (1) effectiveness in terms of the quality of the generated optimal solution set; and (2) efficiency in terms of computational time. Figures 8 to 10 showed that the robustness and reliability of the proposed iMOO model were enhanced.

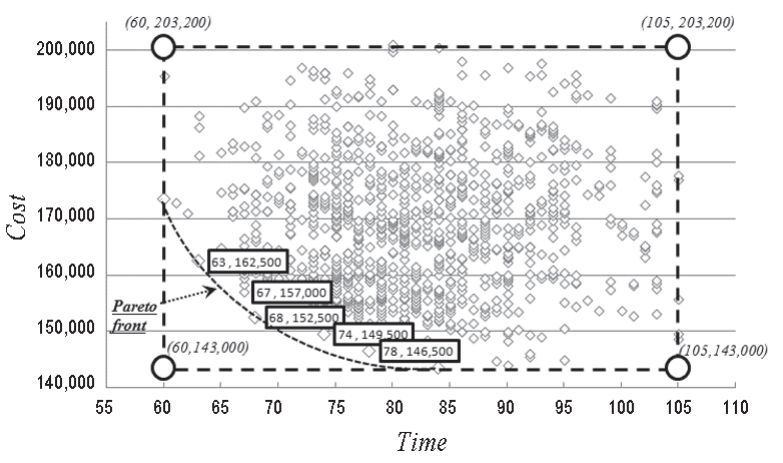

Fig. 8. 1,000 highly ranked populations and the Pareto front in the original coordinate axis

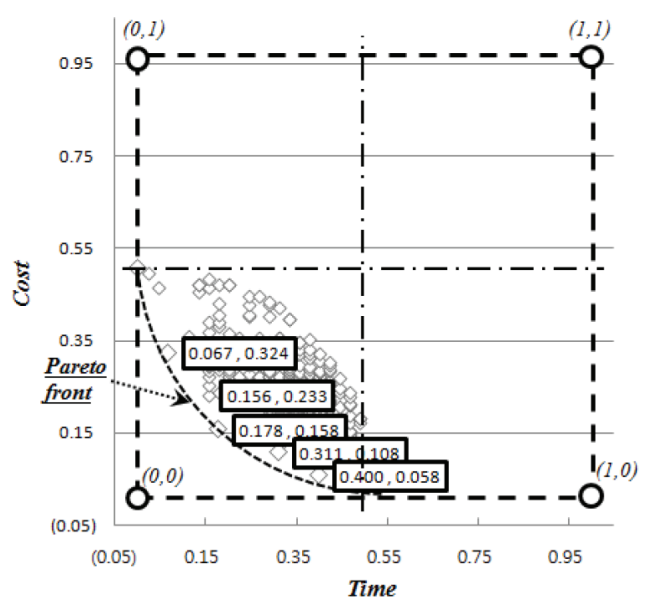

Fig. 9. 250 highly ranked populations and the Pareto front in the standardized coordinate axis 


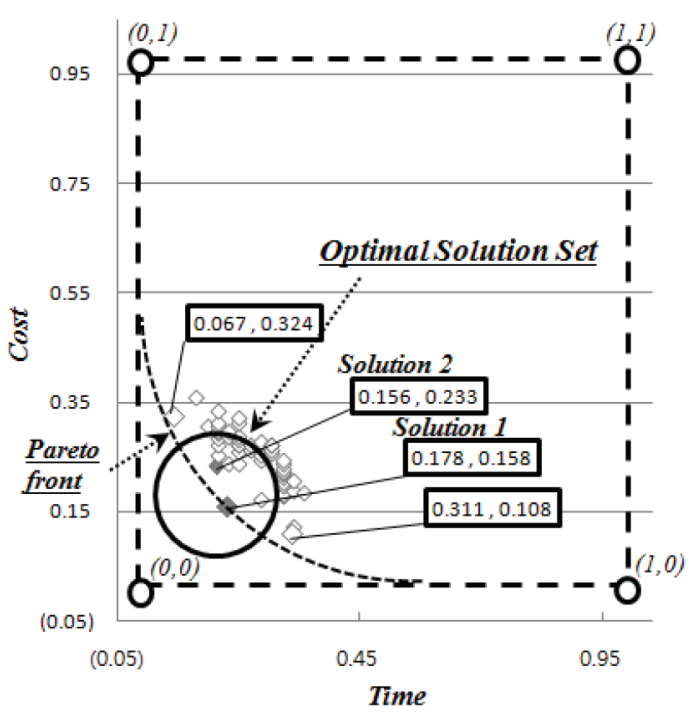

Fig. 10. 50 highly ranked populations, the Pareto front, and the optimal solution set in the standardized coordinate axis

First, the effectiveness of the proposed iMOO model was validated from Figures 8, 9, and 10 as follows: (1) the higher the rank of the population was, the more concentrated on the center of the Pareto front the population became; and (2) the optimal solution set that was finally generated through the GA (the circle area in Fig. 10) was identical to the results of previous studies (Liu et al. 1995; Zheng et al. 2005b). Consequently, given the objective of this research that is to develop more intuitive, simplified, applicable and flexible model to solve the multi-objective optimization problem compared to the previous studies (Liu et al. 1995; Zheng et al. 2005b), it was determined that the effectiveness in terms of the quality of the generated optimal solution set was achieved. Moreover, depending on the decision criteria, the decision-maker can select the more effective one among the optimal solution set. As shown in Figure 10, the two coordinates, Solution $1(0.178,0.158)$ and Solution $2(0.156,0.233)$, are standardized values, while the original values are $(68,152,000)$ and $(67,157,000)$, respectively. For instance, according to the set level of the value of the loss due to construction delay, the optimal so-
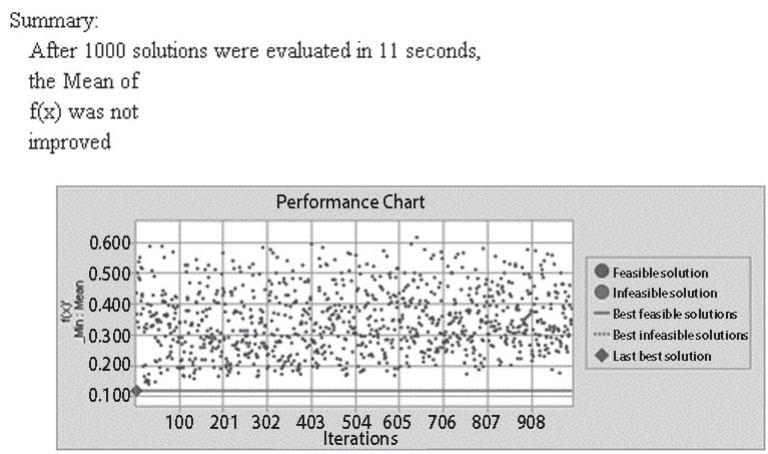

Fig. 11. Optimization summary lution can be changed. If the opportunity cost is $\$ 500 /$ day, the cost of Solution 1 is $\$ 153,000$ (i.e. $152,500+500 *(68-$ $67)=153,000)$. Thus, it was determined that Solution 1 is superior to Solution 2. If the decision-maker sets the opportunity cost at $\$ 4,500 /$ day or more, depending on the project characteristics, however, the cost of Solution 1 will exceed $\$ 157,000$ (i.e. $152,500+4,500 *(68-67)=$ $157,000)$. Thus, it was determined that Solution 2 is superior to Solution 1.

Second, the efficiency of the proposed iMOO model can be validated using the total computational time (shown in Fig. 11). According to the iMOO model developed in this study, the time spent in determining the optimal solution set on a computer $\left[2.8 \mathrm{GHz}\right.$ Intel ${ }^{\mathrm{R}}$ Core $^{\mathrm{TM}}$ i5 processor with $6.00 \mathrm{~GB}$ (2.96 GB available) of RAM] was only 11 seconds. As shown in Figure 11, the results of the 1,000 simulation runs showed no more improvement in the fitness function. It was determined that efficiency in terms of computational time was achieved.

In conclusion, the proposed iMOO model showed improved effectiveness and efficiency, compared to the results of previous studies (Liu et al. 1995; Zheng et al. 2005 b), indicating that the robustness and reliability of the proposed iMOO model was enhanced.

\section{Conclusions}

This study was conducted to develop an iMOO model that can provide the optimal solution set based on the concept of the Pareto front, which involves the following six-phase process: (1) problem statement; (2) definition of the optimization objectives; (3) establishment of the data structure; (4) standardization of the optimization objectives; (5) definition of the fitness function; and (6) introduction of the genetic algorithm.

A simple case was verified using the iMOO model that was proposed in this study. The iMOO model is more intuitive, simplified, applicable and flexible one compared to the previous studies. By using simplified process and equations of the $\mathrm{iMOO}$ model, the optimal solution can be also found in a real project that has considerably more activities. The results can be summarized as follows.

First, to verify the iMOO model developed in this study, a simple case was used. The case had 4,860 possible combinations $(3 * 5 * 3 * 3 * 4 * 3 * 3$; refer to the fourth column of "Construction methods" in Table 1). The optimal solution set could be derived within 11 seconds only. It was shown that an optimized approach to develop the iMOO model would be more effective rather than heuristic method and mathematical programming. Since a real project is considerably more complicated, it takes a considerable time to review all possible combinations using the heuristic method, and the result cannot ensure the reliability of the optimal solution. Furthermore, mathematical programming would take too much effort and time to define an extremely complex relationship. 
Second, in this study, a GA was used to solve a multi-objective optimization problem. Based on the concept of the Pareto front, an attempt was made to derive the optimal solution. This study also simplified the complicated process and equation proposed in previous studies and offered a solution that allows the implementation of the meaningful weight value based on the project characteristics and the owner's requirements. However, although there are various methods of calculating the weight value, that was not considered as a main issue in this study. At the same time, compared to the results of previous studies, the proposed iMOO model showed improved effectiveness and efficiency, indicating that the robustness and reliability of the iMOO model was enhanced.

Third, the proposed iMOO model allowed more optimal solutions from the optimal solution set based on the decision criteria of the decision-maker. By analyzing the trade-off relationship between the time and cost (i.e. the indirect cost or the opportunity cost), the final optimal solution can be selected. Furthermore, the iMOO model showed improved flexibility or applicability and usability against the problems on more than two optimization objectives through the multi-dimensional concept (refer to Fig. 3), according to the problem statement.

The iMOO model developed in this study can be used for several objectives in future research: (1) to ensure the usability of the iMOO model, the research team will apply it to a real project that has considerably more activities; (2) to ensure the extendibility of the iMOO model, the research team will apply it to solve the problems on more than two optimization objectives through the multi-dimensional concept; and (3) to ensure the applicability or flexibility of the iMOO model, the research team will apply it to the other research subject such as the optimal selection of new renewable energy system. The results of this study can be used: (1) to assess more than two optimization objectives (i.e. the initial investment cost, operation and maintenance cost, and $\mathrm{CO}_{2}$ emission trading cost); (2) to take advantage of the weights as the real meanings; (3) to evaluate the four types of fitness functions; and (4) to expand into other areas such as the indoor air quality, materials, and energy use.

\section{Acknowledgements}

This research was supported by Basic Science Research Program through the National Research Foundation of Korea (NRF) funded by the Ministry of Education, Science and Technology (No. NRF-2012R1A2A1A01004376) and by a grant from High-Tech Urban Development Program (11CHUD-C03) funded by the Ministry of Land, Transport and Maritime affairs, South Korea.

\section{References}

Adeli, H.; Cheng, N. 1993. Integrated genetic algorithm for optimization of space structures, Journal of Aerospace Engineering 6(4): 315-328.

http://dx.doi.org/10.1061/(ASCE)0893-1321(1993)6:4(315)
Adeli, H.; Hung, S. 1995. Machine learning-neural networks, genetic algorithms, and fuzzy sets. New York: John Wiley and Sons. $211 \mathrm{p}$.

Adeli, H.; Sarma, K. 2006. Cost optimization of structures-fuzzy logic, genetic algorithm, and parallel computing. West Sussex, United Kingdom: John Wiley and Sons. 222 p. http://dx.doi.org/10.1002/0470867353

Ammar, M. 2011. Optimization of project time-cost trade-off problem with discounted cash flows, Journal of Construction Engineering and Management 137(1): 65-71. http://dx.doi.org/10.1061/(ASCE)CO.1943-7862.0000256

Ansell, M.; Holmes, M.; Evans, R.; Pasquire, C. 2009. Price A. Delivering best value in highways major maintenance schemes: case study, Journal of Construction Engineering and Management 135(4): 235-245.

http://dx.doi.org/10.1061/(ASCE)0733-9364(2009)135:4(235)

Asmar, M.; Lotfallah, W.; Whited, G.; Hanna, A. 2010. Quantitative methods for design-build team selection, Journal of Construction Engineering and Management 136(8): 904-912.

http://dx.doi.org/10.1061/(ASCE)CO.1943-7862.0000194

Balling, R; Powell, B.; Saito, M. 2004. Generating future landuse and transportation plans for high-growth cities using a genetic algorithm, Computer-Aided Civil and Infrastructure Engineering 19(3): 213-222.

http://dx.doi.org/10.1111/j.1467-8667.2004.00349.x

Burns, S.; Liu, L.; Feng, C. 1996. The LP/IP hybrid method for construction time-cost trade-off analysis, Construction Management and Economics 14(3): 265-276. http://dx.doi.org/10.1080/014461996373511

Carvalho, M.; Lozano, M.; Serra, L. 2012. Multicriteria synthesis of trigeneration systems considering economic and environmental aspects, Applied Energy 91(1): 245-254. http://dx.doi.org/10.1016/j.apenergy.2011.09.029

Certa, A.; Galante, G.; Lupo, T.; Passannanti, G. 2011. Determination of pareto frontier in multi-objective maintenance optimization, Reliability Engineering and System Safety 96(7): 861-867.

http://dx.doi.org/10.1016/j.ress.2010.12.019

Chen, P.; Weng, H. 2009. A two-phase ga model for resourceconstrained project scheduling, Automation in Construction 18(4): 485-498.

http://dx.doi.org/10.1016/j.autcon.2008.11.003

Construction Management Association of America (CMAA). 1999. Standard construction management services and practice. $3^{\text {rd }}$ ed. Construction Management Association of America.

Elbehairy, H.; Elbeltagi, E.; Hegazy, T.; Soudki, K. 2006. Comparison of two evolutionary algorithms for optimization of bridge deck repairs, Computer-Aided Civil and Infrastructure Engineering 21(8): 561-572.

http://dx.doi.org/10.1111/j.1467-8667.2006.00458.x

Elbeltagi, E.; Hegazy, T.; Grierson, D. 2005. Comparison among five evolutionary-based optimization algorithms, Advanced Engineering Informatics 19(1): 43-53. http://dx.doi.org/10.1016/j.aei.2005.01.004

Elegbede, C.; Adjallah, K. 2003. Availability allocation to repairable systems with genetic algorithms: a multiobjective formulation, Reliability Engineering \& System Safety 82(3): 319-330. http://dx.doi.org/10.1016/j.ress.2003.08.001

El-Rayes, K.; Kandil, A. 2005. Time-cost-quality trade-off analysis for highway construction, Journal of Construction Engineering and Management 131(4): 477-486.

http://dx.doi.org/10.1061/(ASCE)0733-9364(2005)131:4(477)

Feng, C.; Liu, L.; Burns, S. 1997. Using genetic algorithm to solve construction time-cost trade-off problems, Journal of Computing in Civil Engineering 11(3): 184-189.

http://dx.doi.org/10.1061/(ASCE)0887-3801(1997)11:3(184) 
Fondahl, J. 1961. A noncomputer approach to the critical path method for the construction industry. Technical Rep No. 9. Department of Civil Engineering, Stanford University, Stanford, Calif: The Construction Institute.

Geem, Z. 2010. Multiobjective optimization of time-cost tradeoff using harmony search, Journal of Construction Engineering and Management 136(6): 711-716. http://dx.doi.org/10.1061/(ASCE)CO.1943-7862.0000167

Gen, M.; Cheng, R. 2000. Genetic algorithms \& engineering optimization. New York: Wiley-Interscience. 495 p.

Goldberg, D. 1989. Genetic algorithms in search, optimization, and machine learning. Reading, Mass: Addision-Wesley. 412 p.

Hegazy, T. 1999. Optimization of construction time-cost tradeoff analysis using genetic algorithms, Canadian Journal of Civil Engineering 26(6): 685-697.

http://dx.doi.org/10.1139/199-031

Hegazy, T.; Ersahin, T. 2001. Simplified spreadsheet solutions II: overall schedule optimization, Journal of Construction Engineering and Management 127(6): 469-475.

http://dx.doi.org/10.1061/(ASCE)0733-9364(2001)127:6(469)

Henderickson, C.; Au, T. 1989. Project management for construction. Englewood Cliffs, NJ: Prentice-Hall. 537 p.

Hsieh, T.; Liu, H. 2004. Genetic algorithm for optimization of infrastructure investment under time-resource constraint, Computer-Aided Civil and Infrastructure Engineering 19(3): 203 212. http://dx.doi.org/10.1111/j.1467-8667.2004.00348.x

Huang, H.; Ooka, R.; Chen, H.; Kato, S. 2009. Optimum design for smoke-control system in buildings considering robustness using CFD and genetic algorithms, Building and Environment 44(11): 2218-2227.

http://dx.doi.org/10.1016/j.buildenv.2009.02.002

Jiang, A.; Issa, R.; Malek, M. 2011. Construction project cash flow planning using the pareto optimality efficiency network model, Journal of Civil Engineering and Management 17(4): 510-519. http://dx.doi.org/10.3846/13923730.2011.604537

Kandil, A.; El-Rayes, K.; El-Anwar, O. 2010. Optimization research: enhancing the robustness of large-scale multiobjective optimization in construction, Journal of Construction Engineering and Management 136(1): 17-25. http://dx.doi.org/10.1061/(ASCE)CO.1943-7862.0000140

Konak, A.; Coit, D.; Smith, A. 2006. Multi-objective optimization using genetic algorithms: a tutorial, Reliability Engineering \& System Safety 91(9): 992-1007.

http://dx.doi.org/10.1016/j.ress.2005.11.018

Lam, K.; Palaneeswaran, E.; Yu, C. 2009. A support vector machine model for contractor prequalification, Automation in Construction 18(3): 321-329. http://dx.doi.org/10.1016/j.autcon.2008.09.007

Li, H.; Love, P. 1997. Using improved genetic algorithms to facilitate time-cost optimization, Journal of Construction Engineering and Management 123(3): 233-237.

http://dx.doi.org/10.1061/(ASCE)0733-9364(1997)123:3(233)

Liu, C.; Zhao, C.; Xu, Q. 2012. Integration of electroplating process design and operation for simultaneous productivity maximization, energy saving, and freshwater minimization, Chemical Engineering Science 68(1): 202-214. http://dx.doi.org/10.1016/j.ces.2011.09.024

Liu, L.; Burns, S.; Feng, C. 1995. Construction time-cost tradeoff analysis using LP/IP hybrid method, Journal of Construction Engineering and Management 121(4): 446-454.

http://dx.doi.org/10.1061/(ASCE)0733-9364(1995)121:4(446)

Marseguerra, M.; Zio, E.; Podofillini, L. 2004. A multiobjective genetic algorithm approach to the optimization of the technical specifications of a nuclear safety system, Reliability Engineering \& System Safety 84(1): 87-99. http://dx.doi.org/10.1016/S0951-8320(03)00175-3

Martorell, S.; Villanueva, J.; Carlos, S.; Nebot, Y.; Sanchez, A.; Pitarch, J. 2005. RAMS $+\mathrm{C}$ informed decision-making with application to multi-objective optimization of technical specifications and maintenance using genetic algorithms, Reliability Engineering \& System Safety 87(1): 65-75.

http://dx.doi.org/10.1016/j.ress.2004.04.009

Moradi, H.; Zandieh, M.; Mahdavi, I. 2011. Non-dominated ranked genetic algorithm for a multi-objective mixedmodel assembly line sequencing problem, International Journal of Production Research 49(12): 3479-3499. http://dx.doi.org/10.1080/00207540903433882

Moselhi, O. 1993. Schedule compression using the direct stiffness method, Canadian Journal of Civil Engineering 20(1): 65-72. http://dx.doi.org/10.1139/193-007

$\mathrm{Ng}$, S.; Zhang, Y. 2006. Optimizing construction time and cost using ant colony optimization approach, Journal of Construction Engineering and Management 134(9): $721-728$

http://dx.doi.org/10.1061/(ASCE)0733-9364(2008)134:9(721)

Pagnoni, A. 1990. Project engineering: computer oriented planning and operational decision making. Berlin: Springer. 239 p. http://dx.doi.org/10.1007/978-3-642-75630-6

Prager, W. 1963. A structural method of computing project cost polygons, Management Science 9(3): 394-404. http://dx.doi.org/10.1287/mnsc.9.3.394

Rogoža, A.; Čiuprinskas, K.; Šiupšinskas, G. 2006. The optimisation of energy systems by using 3E factor: the case studies, Journal of Civil Engineering and Management 12(1): 63-68.

Sayin, S.; Kouvelis, P. 2005. The multiobjective discrete optimization problem: a weighted min-max two-stage optimization approach and a bicriteria algorithm, Management Science 51(10): 1572-1581. http://dx.doi.org/10.1287/mnsc. 1050.0413

Šešok, D.; Belevicius, R. 2008. Global optimization of trusses with a modified genetic algorithm, Journal of Civil Engineering and Management 14(3): 147-154. http://dx.doi.org/10.3846/1392-3730.2008.14.10

Šešok, D.; Mockus, J.; Belevicius, R.; Kaceniauskas, A. 2010. Global optimization of grillages using simulated annealing and high performance computing, Journal of Civil Engineering and Management 16(1): 95-101. http://dx.doi.org/10.3846/jcem.2010.09

Siemens, N. 1971. A simple CPM time-cost trade-off algorithm, Management Science 17(6): 354-363. http://dx.doi.org/10.1287/mnsc.17.6.B354

Simanaviciene, R.; Liaudanskiene, R.; Ustinovichius, L. 2012. A new synthesis method of structural, technological and safety decisions (SyMAD-3), Journal of Civil Engineering and Management 18(2): 265-276. http://dx.doi.org/10.3846/13923730.2012.666504

Šostak, O.; Vakrinien, S. 2011. Mathematical modelling of dispute proceedings between investors and third parties on allegedly violated third-party rights, Journal of Civil Engineering and Management 17(1): 126-136. http://dx.doi.org/10.3846/13923730.2011.560628

Sullivan, K. 2011. Quality management programs in the construction industry: best value compared with other methodologies, Journal of Management in Engineering 27(4): 210-219. http://dx.doi.org/10.1061/(ASCE)ME.1943-5479.0000054

Unnikrishnan, A.; Valsaraj, V.; Damnjanovic, I. 2009. Design and management strategies for mixed public private transportation networks: a meta-heuristic approach, Computer-Aided Civil and Infrastructure Engineering 24(4): 266-279. http://dx.doi.org/10.1111/j.1467-8667.2008.00587.x

Venskus, A.; Kalanta, S.; Atkočiūnas, J.; Ulitinas, T. 2010. Integrated load optimization of elastic-plastic axisymmetric plates at shakedown, Journal of Civil Engineering and Management 16(2): 203-208. http://dx.doi.org/10.3846/jcem.2010.22 
Zheng, D.; Ng, S. 2005b. Stochastic time-cost optimization model incorporating fuzzy sets theory and nonreplaceable front, Journal of Construction Engineering and Management 131(2): 176-186.

http://dx.doi.org/10.1061/(ASCE)0733-9364(2005)131:2(176)

Zheng, D.; Ng, S.; Kumaraswamy, M. 2004. Applying a genetic algorithm-based multiobjective approach for timecost optimization, Journal of Construction Engineering and Management 130(2): 168-176.

http://dx.doi.org/10.1061/(ASCE)0733-9364(2004)130:2(168)
Zheng, D.; Ng, S.; Kumaraswamy, M. 2005a. Applying pareto ranking and niche formation to genetic algorithm-based multiobjective time-cost optimization, Journal of Construction Engineering and Management 131(1): 81-91. http://dx.doi.org/10.1061/(ASCE)0733-9364(2005)131:1(81)

Choongwan KOO. He is a Post-doctoral Fellow at the Department of Architectural Engineering of Yonsei University, Seoul, Korea. He has received a $\mathrm{PhD}$ degree at Yonsei University. Before attending Yonsei University, he worked at international Construction Management company called 'HanmiGlobal' as a Research Engineer. His primary research areas include time and cost optimization for construction projects, building energy efficiency, new renewable energy, solar photovoltaics, carbon emissions reduction, life cycle cost, and life cycle assessment.

Taehoon HONG. He has received a PhD degree at Purdue University. He is an Associate Professor at the Department of Architectural Engineering of Yonsei University, Seoul, Korea. He is an Editor-in-Chief in the Journal of Construction Engineering and Project Management, KICEM and a Corresponding Member of Editorial Board in the Journal of Management in Engineering, ASCE. Also, he is a member of academic or practical institute such as AIK, KSCE, ASCE, and KICEM. His main research areas include life cycle cost analysis, life cycle assessment, infrastructure asset management, facility management, and construction project cost control.

Sangbum KIM. He is an Associate Professor at the Department of Civil and Environmental Engineering of Dongguk University, Seoul, Korea. He has received a PhD degree at University of Texas at Austin. Before joining the Doongguk University, he worked at Construction Industry Institute (CII). He has been helping the construction industry, especially in the area of productive analysis, construction contract and claim, information management and risk management. In particular, he has conducted extensive research funded by government organization such as Ministry Land, Transport and Maritime Affairs (MLTM). 